\title{
Visual Research Data: an Infographics Primer
}

\author{
Robin M. Featherstone
}

\section{Introduction}

They may be a hot topic in health research and libraries, but infographics are not new. Information visualizations have a long history of use in medicine, particularly epidemiology. Now ubiquitous in modern urban landscapes, infographics are rebranded knowledge assemblages for an information age. Amateur designers use web-based tools to create ephemeral infographics that are rapidly disseminated via social media networks. The best examples of graphic data displays utilize established design principles to increase the impact of scholarly research. Inexpensive or free web tools can provide graphic elements and design templates, but effective information visualizations still require compelling data and logical narratives. Infographics communicate research findings, but the immense scale of production makes classification, description, access, and preservation challenging.

\section{Problematic definitions and a long history}

When I mentioned to an epidemiologist friend that I was writing about infographics, he replied he loved the concept but hated the name. After struggling to find a concrete definition that clearly distinguished infographics (an obviously blended word, or portmanteau, of information and graphics) from data or information visualizations - or even from graphical charts or data maps-I understood. In my best effort to define infographics, I realized they are either the same as, or very closely related to, existing terms for the graphical representation of data. So rather than focusing on how they differ, here I hope to explain why these graphics have been rebranded and labeled a trend in research circles and libraries.

As a form of knowledge assemblage, infographics use text and numbers, charts, graphs or maps, and characters to transform data into visually accessible arguments. Examples abound, especially in medicine. In the 1850s, for instance, Florence Nightingale's Rose famously illustrated that more Crimean War soldiers died from poor hospital sanitation than from enemy action [1]. In that decade Dr. John Snow and Reverend Henry Whitehead separately charted and mapped a vicious cholera outbreak centered in the Broad Street area of St. James, Westminster.
They argued, separately, that the maps appeared to demonstrate that local water sources were the source of the outbreak, and by extension cholera generally [2].

Infographic is a new name for an old, old thing. Some have even argued that 32,000 year old cave paintings are an early form of infographic [3], although it seems foolish to apply the modern word to so ancient a medium. So, if information visualizations have been around for centuries, what makes them a critical feature of contemporary investigation?

\section{Web-based creation tools and dissemination via social media}

Infographics are ubiquitous in modern urban life and its myriad landscapes. The 2002 music video for "Remind Me" by Norwegian electronic duo Röyksopp, prophetically illustrates (using infographic elements) how information visualizations surround us (http://www.youtube.com/ watch? $\mathrm{v}=1 \mathrm{Xhdy} 9 \mathrm{zBEws})$. Infographics are everywhere: graphics embedded in advertisements, news stories, and of course, schematic subway maps. On the Internet various forms of infographics multiply at a viral rate.

Graphic information displays may be ancient, but the methods by which they are created and disseminated are evolving rapidly. Google Trends data for "infographic" and "infographics" show virtually zero searches until 2010, when the number of searches for these terms increases dramatically. The word is a construct of a social media age that reflects the availability of web tools for creating and disseminating user-generated graphics. Design products (e.g., Piktochart, Ease.ly, Visual.ly, etc.) provide amateur designers with the ability to create their own web-based infographics, and media sites that rely on user-generated content (e.g., Twitter and Pinterest) allow for rapid dissemination via social networks.

I first observed evidence of infographic dissemination of research while scrolling through Twitter channels on my smartphone. Accounts for health agencies, research institutes, and associations (e.g., @CDCgov,@CIHR_IRSC, @ AmerMedicalAssn) were experimenting with embedded infographics. It struck me that visualizations based on health research data were being distributed in digital

Robin M. Featherstone. ${ }^{1}$ Alberta Research Centre for Health Evidence, Department of Pediatrics, University of Alberta.

${ }^{1}$ Corresponding author (e-mail: feathers@ualberta.ca) 
miniature through the Twitter marketplace, and that this was a new communication channel for researchers.

\section{Health-related infographic dissemination via social media}

Some preliminary classification suggests that health promotion infographics are common. These public health infographics, like this example from Sunnybrook Hospital that urges us to "Climb the stairs to better health" (http:// health.sunnybrook.ca/wp-content/uploads/2014/05/takethe-stairs-infographic.jpg), visualize research data to support promotional messages to eat healthy foods, drink in moderation, be active, wash hands, and to prevent illness by making healthy personal choices. Other examples of public health infographics include these safety messages from the U.S. Centres for Disease Control and Prevention (CDC) about listeria (http://www.cdc.gov/vitalsigns/listeria/ infographic.html), and excessive alcohol use (http://www. cdc.gov/alcohol/pdfs/excessive_alcohol_use.pdf). All of these infographics were created or adapted for the web and disseminated via social media.

Health inequities research contributes to another category of health-related infographics that is being promoted by global nonprofit organizations and charities. In these examples, we see how the data make a compelling argument for social justice, as in these distorted maps that illustrate how many people have been internally displaced by conflict and violence, (http://www.viewsoftheworld.net/wp-content/ uploads/2014/06/RefugeesMap_PeopleInternallyDisplaced 2014.jpg), and the global distribution of the health worker shortage (https://twitter.com/PSIimpact/status/4546848176 16273408/photo/1).

Both the health promotion and inequalities infographic categories illustrate how powerful visual messages can be in conveying an argument. Research data are often lost in scholarly publications that follow an "IMRAD" structure (Introduction, Methods, Results, And Discussion). Conversely, data with minimal exposition can be more compelling than an academic journal article because they communicate research findings quickly.

Around the same time as health organizations such as the CDC began disseminating promotional messages via Twitter, the Alberta Research Centre for Health Evidence (ARCHE) started using infographics to create summaries of systematic reviews for healthcare professionals, patients, and caregivers [4]. ARCHE also began integrating infographic elements into conference posters [5] that the centre's Twitter feed (https://twitter.com/arche4evidence) shared with the centre's audience of online followers. Altmetrics (also known as alternative metrics) collected from analytic tools (Twitter Analytics, Twitonomy) suggested these visual tweets yielded more online mentions and generated more media traffic than text-based messages.

\section{Infographics and libraries}

Researchers are not the only group to embrace infographic dissemination via social media. There are hundreds of examples of infographics related to libraries and librarians on Pinterest boards (http://www.pinterest.com/ proquest/infographics-for-libraries-and-librarians/; http:// www.pinterest.com/yeoldefort/library-infographics/; http:// www.pinterest.com/comlibrary/library-infographics/), and even a website for sharing the creative designs and infographics of librarians (http://librariandesignshare.org/).

Librarians and libraries are using infographic software to create outreach material and to share their research. Some academic librarians are also teaching infographic editors and design principles by offering workshops and supporting LibGuides [6]. Infographics appeal to librarians and researchers for the same reasons that small businesses embrace these visual marketing tools: infographics can be cost-effective ways to promote your message and your brand.

\section{The backlash against infographics}

Despite widespread enthusiasm for infographics, do-ityourself visualizations have their share of critics. Shortly after the rise of the rebranded "infographic" in 2010, there was an inevitable backlash from academically or professionally trained graphic designers and data specialists [7-9]. Their complaints included the large number of infographic "abominations" being created by "designdeficient morons" [9]. Rude comments aside, their judgment about the quality of amateur infographics is sound. The best infographic paints a picture with data (i.e., a map that shows a global distribution of internally displaced people shows where humanitarian aid is needed). Conversely, the worst infographics oversimplify complex issues and manipulate viewers into reaching false conclusions.

The principles for creating graphic representations of research data are masterfully explained by Edward $\mathrm{R}$. Tufte in his self-published nonfiction book, The Visual Display of Quantitative Information [10]. Tufte reminds us of the GIGO (Garbage In, Garbage Out) principle in information technology when he wrote that no matter how clever or fancy, bad data cannot be rescued by a graphic [10]. A good infographic is built on solid research, but many modern examples on Twitter and Pinterest are disparate collections of statistics assembled for the purposes of selling commercial products.

Even if quality research underlies an infographic, it takes more than a few charts and some iconographic characters to make the display visually engaging or effective. The following case example of designing conference posters effectively illustrates how design principles are generally lacking from even this most common of research displays.

\section{Displaying research graphically}

Not unlike most researchers, I start the process of creating a conference poster by digitally pasting my abstract on an oversized PowerPoint slide (or at least, I used to start this way). I would expand upon my abstract's text, trying to cram in as much "critical" information as possible about the project, and then add a few charts and images at the last minute. I knew my posters were failing to engage viewers, but I had never learned how to present research data graphically. 
Advice from graphic designers and data experts for creating effective infographics $[11,12]$ is well worth reviewing before embarking on a visualization project like assembling data for a conference poster. I learned my poster design process was flawed on many levels. My first mistake was to begin with a textual abstract, when I should have started with the research data itself [12]. Another mistake I made was failing to identify a narrative that the research data supported.

Integrating a narrative arc, or storytelling elements, into journal publications has been promoted as a way to make scholarly writing more engaging $[13,14]$. Much in the same way, a narrative is an essential element in any visualization of research data, particularly if that visualization is intended to stand alone.

Now when I design a conference poster, I decide on the purpose of assembling my data and the narrative I want to support using visual elements. Only once I have identified a hierarchy of data that culminates with a "hero statistic," (i.e., a compelling finding from my research data) do I open a design editor. I select visualizations suited to the data and then develop a wireframe to show the relationship between data elements. I found my poster no longer needed big blocks of texts to describe the project because the narrative was evident from the visual display.

\section{Online tools for creating infographics}

Finding an online tool for creating an infographic is like finding sand at the beach; the problem is finding a tool that works for you. To start, I recommend reviewing a curated list such as one of those maintained by academic librarians $[6,15]$. I also suggest trying a few products and then deciding which will work best for your project.

For a recent poster design project, I used Piktochart (http://piktochart.com/) to create charts in a compatible format with a PowerPoint template customized to print large-scale posters. This process worked well for creating a poster with graphic data visualizations. Another colleague who uses online design tool swears by Ease.ly (http://www. easel.ly/) because of the quality of its ready-made templates and the usability of its online editing tools, but her infographics are intended to be disseminated primarily over the web and do not need to be printed in large scale.

Whether you use Piktochart, Ease.ly, Canva, Infogr.am, Visual.ly, or whatever tool is readily available when you start to design, do not underestimate the challenge of expressing data with engaging visuals. Professional graphic designers create impressive infographics that set high standards for imitators. Nevertheless, researchers and librarians who lack design training can still increase the impact of their research by applying basic information visualization principles to their publications and presentations.

\section{Future directions and challenges}

Information-processing research seeks to understand how the human brain responds to displays of complex datasets [16] and which visual elements are the most appealing [17], comprehensible, and memorable [18-20]. But there is a current knowledge-to-practice gap between what we know about effective visuals and the informational graphics we create. For example, research showed in 2006 that humans prefer curved visual objects $[17,21]$ but linear bar charts and data tables remain dominant figures in scientific papers. We are far from having standards for data visualizations, but we do have evidence to inform the design process. To put neurosciences research into practice requires knowledge translation projects to establish evidence-informed design principles in communities of practice.

\section{Visualization taxonomies and curation}

To build communities of practice for designing research displays, we also need a common language to describe visualizations. There have been a handful of projects to create visualization taxonomies [22-24]. These typically include categories for charts, maps, time series, hierarchies, etc. One taxonomy includes "infographic" as a separate visualization from charts or maps [22], further confounding our understanding as the taxonomy supports one type of visualization being included in another. Efforts to categorize and describe information visualizations could benefit from the expertise of information scientists and librarians. While researching this column, I found a particular problem in searching for research about infographics. Keyword searches for infographics will yield any visualization described that way, and the term "infographic" is often part of the title. The results are a confusing mess of infographics that have nothing to do with visualization research. Subject headings based on common taxonomies will help distinguish graphic information displays, and discreet metadata schema will aid in separating research about infographics from research that uses infographics.

Another particular problem for modern-day infographics is how to identify and preserve important examples for posterity. These born-digital objects are buried in journal articles, websites, and social media mentions. Infographics are difficult to find and often too ephemeral to capture. There are homegrown projects to collect infographics, like the website Infographic Journal (http://infographicjournal.com/), but there is no commitment to maintain these repositories. If infographics are emblematic knowledge assemblages of the information age, then they are also cultural objects worthy of preservation and access. Further, if infographics are communicating publicly funded research data, then creators have a responsibility to ensure their accessibility. As with visualization taxonomies, infographic repositories and digital archives are projects uniquely suited to information scientists and librarians.

\section{Conclusions}

Infographics are knowledge assemblages of an information age but depend on age-old design principles. Easily available web tools may help researchers and librarians express data visually, but high quality research data should always underlie do-it-yourself infographics. Cost-effective opportunities to create and disseminate infographics via social networks have proven attractive to health research 
centers, agencies, institutes, and medical associations, in addition to global nonprofits. These creative efforts to disseminate research narratives may be hindered by current challenges to identify, describe, and preserve infographics. Both ubiquitous and ephemeral, infographics pose unique opportunities and challenges for researchers and information professionals.

\section{Acknowledgement}

I gratefully acknowledge the assistance of Dr. Tom Koch who reviewed drafts of this article. His knowledge of the history of medical cartography was of material assistance.

\section{References}

1. Cressey D. Infographics: truth is beauty. Nature. 2014; 507(7492):304-5. doi: 10.1038/507304a.

2. Koch T. Cartographies of disease: maps, mapping, and medicine. Redlands, CA: ESRI Press; 2005.

3. visual.ly. History of Infographics n.d. [cited 28 August 2014]. Available from: http://visual.ly/history-of-infographics.

4. Hartling L, Crick K, Thomson D. Translating knowledge from systematic reviews: evaluating infographics and critical appraisals. Cochrane Canada Symposium; April 24, 2014; Ottawa, ON, Canada.

5. Featherstone R, Hamm M, Hartling L. Communicating and conducting research through social media: lessons learned from an academic research centre. Canadian Health Libraries Association; June 18, 2014; Montreal, QC, Canada.

6. Brecher D. Infographic DIY: Claremont Colleges Library LibGuide; 2014 [cited 28 August 2014]. Available from: http:// libguides.libraries.claremont.edu/content.php?pid $=578071 \&$ sid $=4764825$.

7. Rogers S. Data visualisation: in defence of bad graphics. The Guardian: Datablog. October 17, 2011 [cited 28 August 2014]. Available from: http://www.theguardian.com/news/da tablog/2011/oct/17/data-visualisation-visualization.

8. Sonderman J. People are tired of bad infographics, so make good ones: Poynter.org; 2011 [cited 28 August 2014]. Available from: http://www.poynter.org/how-tos/newsgatheringstorytelling/visual-voice/149636/people-are-tired-of-bad-info graphics-so-make-good-ones/.

9. Diaz J. Stop Already with the F*cking "Infographics": Gizmodo; 2011 [cited 28 August 2014]. Available from: http://gizmodo.com/5846087/stop-already-with-the-fcking-in fographics.

10. Tufte ER. The visual display of quantitative information. Cheshire, CT: Graphics Press;1983.
11. Hitz S, Hart H. How to Design Infographics and Use Them to Increase Blog Traffic: Traning Authors; 2013 [cited 28 August 2014]. Available from: http://www.trainingauthors. com/how-to-design-infographics/\#ixzz2m36EKPtX.

12. Smith J. 10 Steps to Designing an Amazing Infographic: Co.DESIGN; 2012 [cited 28 August 2014]. Available from: http://www.fastcodesign.com/1670019/10-steps-to-designingan-amazing-infographic.

13. Nash RJ. Liberating scholarly writing: the power of personal narrative. New York, NY: Teachers College Press; 2004.

14. Brumley C. Academic and storytelling are not incompatiblehow to reduce the risks and gain control of your research narrative. LSE Impact Blog;2014. Available from: http:// blogs.1se.ac.uk/impactofsocialsciences/2014/08/27/academicstorytelling-risk-reduction/.

15. Giustini D. Infographics: HLWIKI International; 2014 [cited 28 August 2014]. Available from: http://hlwiki.slais.ubc.ca/ index.php/Infographics.

16. Gershon N, Eick SG, Card S. Information visualization. Interactions. 1998;5(2):9-15. doi: 10.1145/274430.274432.

17. Bar M, Neta M. Humans prefer curved visual objects. Psychol Sci. 2006;17(8):645-8. doi: 10.1111/j.1467-9280.2006. 01759.x.

18. Borkin MA, Vo AA, Bylinskii Z, Isola P, Sunkavalli S, Oliva A, et al.. What makes a visualization memorable? IEEE Trans Visual Comp Grap. 2013;19(12):2306-15. doi: 10.1109/ tvcg.2013.234.

19. Bateman S, Mandryk RL, Gutwin C, Genest A, McDine D, Brooks C. Useful Junk? The Effects of Visual Embellishment on Comprehension and Memorability of Charts. Chi2010: Proceedings of the 28th Annual Chi Conference on Human Factors in Computing Systems, Vols 1-4. 2010:2573-82.

20. Isola P, Xiao JX, Torralba A, Oliva A. What makes an image memorable? Proc Cvpr Ieee. 2011:145-52.

21. Bar M, Neta M. Visual elements of subjective preference modulate amygdala activation. Neuropsychologia. 2007;45(10): 2191-200. doi: 10.1016/j.neuropsychologia.2007.03.008.

22. Lee E. A Taxonomy of Data Visualization: visualizing.org; 2012 [cited 28 August 2014]. Available from: http://visualizing.org/stories/taxonomy-data-visualization.

23. Behrens C. The Form of Facts and Figures. Master of Arts in Design in the Interface Design program Master Thesis, Potsdam University of Applied Sciences;2008.

24. Heer J, Bostock M, Ogievetsky V. A Tour Through the Visualization Zoo 2010 [cited 28 August 2014]. Available from: http://homes.cs.washington.edu/ jheer//files/zoo/. 